EDITORIAL

\title{
Comunicación científica: modelos actuales y evaluación de los investigadores
}

\author{
Scientific communication: current models and evaluation of researchers
}

La comunicación científica es un componente esencial de la vida académica; a través de la misma se comparte, difunde y publica los resultados de las investigaciones poniéndolos a disposición de la comunidad académica y científica mundial y de la sociedad en general. ${ }^{1}$ En las últimas dos décadas, la comunicación científica se ha transformado enormemente debido a la digitalización e introducción de herramientas de comunicación tecnológica. Esta evolución tiene efectos sobre cómo se realiza la investigación, su publicación y la evaluación de los investigadores.

En 2002, un grupo de científicos y académicos crearon la iniciativa de Budapest de Acceso Abierto. ${ }^{2}$ El propósito era viabilizar el acceso abierto a las publicaciones científicas difundidas electrónicamente, ya que el aumento abusivo de los costos de suscripciones de revistas científicas, principalmente en las áreas de ciencia, tecnología y medicina, dio origen a lo que se conoció como la crisis de las publicaciones periódicas. ${ }^{3}$ El acceso abierto se define como la disponibilidad libre en internet, permitiendo que cualquier usuario lea, descargue, copie, distribuya, imprima, busque, vincule los textos completos, o utilice para cualquier propósito legal, sin barreras financieras, legales o técnicas, dichas publicaciones científicas. ${ }^{2}$ En el modelo tradicional de publicación, donde casas editoriales gestionan el proceso de revisión y publicación, los lectores realizan un pago para acceder a las publicaciones. En el acceso abierto, a los lectores no se les cobra por leer y no hay cuota de suscripción a la revista, sino que el autor o una institución de financiación pagan por la publicación del artículo. Este costo se denomina Cargo por Procesamiento de Artículos (APC, por sus siglas en inglés Article Processing Charges). En la actualidad se conocen varias formas de publicaciones en acceso abierto:4 1) Dorado: revistas totalmente en Acceso Abierto, 2) Híbrido: revistas de suscripción que ofrecen publicar en acceso abierto de forma inmediata mediante pago APC, 3) Bronce: lectura en acceso abierto, pero sin licencia de reutilización, 4) Verde: repositorios institucionales o temáticos.

Actualmente nos encontramos en un estado de transición donde todos estos modelos de publicación y acceso a las publicaciones científicas coexisten. Uno de los impactos no deseados del acceso abierto es la proliferación de las revistas conocidas como depredadoras, las cuales, aprovechando la necesidad urgente de publicar instalada actualmente en la comunidad académica y científica, ofrecen publicación rápida a bajo costo, sin los procesos editoriales requeridos, incluyendo la revisión por pares. Es imperativo que los autores revisen la calidad de toda revista y casa editorial en la cual desean publicar, indepen- dientemente del modelo. Recientemente el Manifiesto de Hong Kong para evaluar los investigadores y fomentar la integridad de la investigación, ${ }^{5}$ realizó un llamado enérgico indicando que, si la investigación va a beneficiar a la sociedad, debe priorizarse, diseñarse, llevarse a cabo y publicarse de acuerdo con los principios y estándares de la integridad de la investigación individual y organizativa. Los principios expresados en el Manifiesto fueron desarrollados con la idea de que su implementación podría ayudar en la forma en que los investigadores sean evaluados para el avance profesional con el fin de fortalecer la integridad de la investigación. Los cinco principios son: Prácticas de investigación responsables, Informes transparentes, Ciencia abierta, Valoración de diversidad de tipos de investigación y Reconocimiento de todas las contribuciones a la investigación y la actividad académica.

La Revista Médica Hondureña, en su esfuerzo de fortalecimiento y mejora continua, promueve que sus publicaciones beneficien a la sociedad, con la meta principal de ser puntual y mantener la calidad de acuerdo a los parámetros bibliométricos bajo los cuales es evaluada. Este es un esfuerzo institucional que requiere del acompañamiento de los autores, revisores y lectores.

Jackeline Alger, MD, PhD

Directora

\section{REFERENCIAS}

1. Das A. Introduction to Scholarly Communication. In: UNESCO Curriculum for Researchers, Module 1: Scholarly Communications [Internet]. Paris: UNESCO; 2015.p.5-16. [Acceso diciembre 2019]. Disponible en http:/l eprints.rclis.org/24814/

2. Budapest open access initiative. [Internet]. Budapest; 2002. [Acceso diciembre 2019]. Disponible en https://www.budapestopenaccessinitiative. org/read

3. Nassi-Caló L. El acceso abierto como alternativa de sustentabilidad en la comunicación científica. SciELO en Perspectiva [Internet]. 2016 [Acceso diciembre 2019]. Disponible en https://blog.scielo.org/es/2016/01/14/elacceso-abierto-como-alternativa-de-sustentabilidad-en-la-comunicacioncientifical

4. Red de Bibliotecas Universitarias Españolas. Medición del acceso abierto en las universidades españolas y el CSIC (2014- 2018). [Internet] España: REBIUN; 2019. Colección Estudios e Informes. [Acceso diciembre 2019]. Disponible en: http://rebiun.xercode.es/xmlui/bitstream/handle/20.500.11967/354/Medicion_acceso_abierto_REBIUN_2014_2018_informe $\% 20$ final.pdf?sequence $=1$

5. Moher D, Bouter L, Kleiner S, Glasziou P, Sham M, Barbour V, et al. The Hong Kong manifesto for assessing researchers: fostering research integrity. [Preprint] 2019 [Acceso diciembre 2019]. Disponible en https://wcrif. org/images/2020/HKP/HKPs preprint - English.pdf 